\title{
An introduction to medicalization
}

Keywords: adults, pathologies, biomedicine

children, medicalization, technology,

\section{Mini review}

From medical practice with adults and children, it becomes possible to observe fundamental elements that focus upon contemporary culture and raise investigations with the intent of bringing greater subsidies to the practice. Among the current relevant factors for the constitution of subjectivities, medicalization stands out for being an extension of the domain of medicine to other fields of knowledge. Medical treatments for human behaviors and suffering have been seen as something normal, commonplace and even a synonym for progress, technology and innovation. However, the generalized use of psychotropic drugs also exposes the artificialization of the human mind and body, placing in question the frontiers between nature and culture. Thus, this study seeks to present the concept of medicalization, highlighting the importance of the iatrogenic effects of medical treatment.

Among the many relevant issues that currently focus upon medical and psychological practices, medicalization has a standout role. Arousing ever more interest among academics and researchers, who seek to bring greater subsidies to clinical practice with adults and children, the concept of medicalization refers to the political character of medicine, including culture, the contemporary individual and the suffering he/she bears, through which he/she speaks of himself/herself and the surrounding world. If, on one hand, medicalization may wrongly suggest a though process that restricts itself to the strict use of medication and the incidence of pathologies, on the other, it calls attention to pathologization, the standardization and normalization of phenomena that are inherent to human existence.

Post-modern societies are submitted to a continuous and undefined process of medicalization. ${ }^{1}$ In this sense, it is worth thinking that medicalization is a process of the progressive expansion of the field of intervention of biomedicine by means of the redefinition of human experiences and behaviors as if they were medical problems. ${ }^{2}$ According to this trend, medical treatments for human behaviors and suffering have been seen as something normal, commonplace and even a synonym for progress, technology and innovation. With respect to technology, the bilogicist view is hegemonic in the health sciences, which sustains a medicine that seeks evidence, targets symptoms and uses psychotropic medication as a basis for the treatment of human suffering. This medication has been considered a consumer good and is associated to discourses for the promotion of health, quality of life, well-being and happiness. ${ }^{3}$

According to the perspective that plagues contemporaneity and undermines the possibility of questioning, through which the subject may emerge, as a result of the never ending search for well-being and quality of life, everything that diverges from the script understood as "normal" of completeness and full happiness can and should be medicalized. Thus, medicalization refers to the expansion of the jurisdiction of medicine to new domains, especially those that are related to problems of a moral, legal or criminal order. Medicine has transformed itself into a social control device, assuming a regulatory function that beforehand was held by the church and the judiciary. Among the areas of medicine that deserve to be highlighted with
Volume 2 Issue I - 2018

\author{
Luciana Azevedo \\ Departamento de Psicologia, Brazil
}

Correspondence: Luciana Azevedo, Departamento de Psicologia Rua Marqu $\tilde{A}^{\mathrm{a}} \mathrm{s}$ de SÃ $£$ V Vicente, PUC-Rio, 225 -

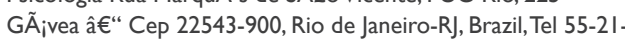
995103239,Email lucianajaramillo@msn.com

Received: July 18, 2017 | Published: January 12, 2018

respect to medicalization, is psychiatry that has had its vocabulary intensely spread over the last (approximately) thirty years. The unchecked medicalization process is favored by the wide array of symptoms and means of diagnostics present in the manuals, especially the DSM-Diagnostic and statistical manual of mental disorders, that, currently, is in its fifth edition. According to this manual, many events in life may be registered as being related to mental disorders., ${ }^{4,5}$

Caponi $^{5}$ highlights that in relation to the field of mental health, since it has unstable, diffuse and ambiguous borders between the normal and the pathological, this makes possible the growing process through which conduct that is part of childhood is classified as "abnormal or pathological". A space of knowledge that Foucault ${ }^{6}$ called "medicine of the non pathological" has consolidated itself. Thus, now, behaviors that is part of childhood and suffering inherent to the human condition, has entered into the psychiatric logic.

\section{Conclusion}

Investigations with respect to medicalization are directed to the analysis of the political intervention of medicine on the social body, by means of the establishment of moral codes of conduct, the prescription and proscription of behaviors, which would make individuals dependent of the knowledge produced by the educationaltherapeutic healthcare agents. The widespread use of psychotropic drugs also exposes the artificialization of the human mind and body, questioning the frontiers between nature and culture. Medicine begins to intervene in the health of individuals that are nor sick, but who demand pharmacological help to manage the difficulties of existence. People are increasingly turning to medication to handle the pressures and suffering generated by contemporary life. However, it is necessary to consider the iatrogenic effects of medical treatment, as well as its impact on the production of subjectivities.

\section{Acknowledgements}

None.

\section{Conflict of interest}

The author declares no conflict of interest.

\section{References}

1. Castro E. Vocabulário de Foucault. Belo Horizonte, Autêntica, Brazil: Springer; 2009. $480 \mathrm{p}$. 
2. Tesser CD. Medicalização social (I): O excessivo sucesso do epistemocídio moderno na saúde. Interface Comunic Saúde Educ. 2006;10(19):61-76.

3. Guarido R. A biologização da vida e algumas implicações do discurso médico sobre a educação. In: CB Angelucchi editors. Medicalização de crianças e adolescentes: conflitos silenciados pela redução de questões sociais a doenças de indivíduos. Casa do Psicólogo, São Paulo: Springer 2010. p. 27-39.
4. Guarido R. A medicalização do sofrimento psíquico: considerações sobre o discurso psiquiátrico e seus efeitos na educação. Educ pesqui. 2007;33(1):151-161.

5. Caponi S. Vigiar e medicar - o DSM-V e os transtornos ubuescos na infância. In: Caponi S, editors. Vigiar e medicar: estratégias de medicalização da infância. Liber Ars, São Paulo, Brazil: Sptinger; 2016. p. 47-60.

6. Foucault M. Abnormal. Martins fonts, São Paulo, Brazil: Springer; 2013. 